OPEN ACCESS

Edited by:

Chanam Lee,

Texas A\&M University, United States

Reviewed by:

Alexjandro C. Daviano EBSCO Health, United States

Angela M. Goins,

University of Houston-Downtown,

United States

${ }^{*}$ Correspondence:

Nai-Wei Hsu

davidnwh@ms28.hinet.net

Specialty section

This article was submitted to

Aging and Public Health,

a section of the journal

Frontiers in Public Health

Received: 21 December 2019

Accepted: 19 June 2020

Published: 31 July 2020

Citation:

Lin Y-H, Chen H-C, Hsu N-W and

Chou P (2020) Validation of Global

Self-Rated Health and Happiness Measures Among Older People in the

Yilan Study, Taiwan.

Front. Public Health 8:346.

doi: 10.3389/fpubh.2020.00346

\section{Validation of Global Self-Rated Health and Happiness Measures Among Older People in the Yilan Study, Taiwan}

\author{
Yen-Huai Lin ${ }^{1,2}$, Hsi-Chung Chen ${ }^{3}, \mathrm{Nai}-\mathrm{Wei} \mathrm{Hsu}^{2,4,5,6 *}$ and Pesus $\mathrm{Chou}^{2}$ \\ ${ }^{1}$ Department of Medical Imaging, Cheng Hsin General Hospital, Taipei, Taiwan, ${ }^{2}$ Community Medicine Research Center, \\ National Yang-Ming University, Taipei, Taiwan, ${ }^{3}$ Department of Psychiatry and Center of Sleep Disorders, National Taiwan \\ University Hospital, Taipei, Taiwan, ${ }^{4}$ Division of Cardiology, Department of Internal Medicine, National Yang-Ming University \\ Hospital, Yilan, Taiwan, ${ }^{5}$ Department of Medicine, School of Medicine, National Yang-Ming University, Taipei, Taiwan, ${ }^{6}$ Public \\ Health Bureau, Yilan, Taiwan
}

Background: Single-item measures of physical and mental health are feasible for older adults, but their validity for that age group is unclear. This study tested validity of a global self-rated health and a global self-rated happiness measure in a large sample of community-dwelling older adults in Taiwan.

Methods: A cross-sectional sample of 3,982 men and women aged 65 or older in Yilan, Taiwan, provided data on global self-rated health and happiness using 100-point numerical scales. The Physical Component Summary of the 12-Item Short Form Health Survey (version 2) and the Groningen Activity Restriction Scale were used to test the validity of the self-rated health item. The Mental Component of that 12 -item scale and the Hospital Anxiety and Depression Scale were validators regarding the self-rated happiness item. Criterion validity was tested using the 12-Item Short Form Health Survey (version 2).

Results: The correlations between the self-rated health and happiness measures and the 12-Item Short Form Health Survey (version 2) validators were positive and statistically significant, supporting convergent validity. Sufficient divergent validity was demonstrated through the negative and significant relationship between the self-rated health item and the Groningen Activity Restriction Scale scores and the negative and significant relationship between the self-rated happiness item and the Hospital Anxiety and Depression Scale. Optimal cut-off scores for physical and mental health states depended on age and gender.

Conclusion: The global self-rated health and happiness measures were validated. Cut-off scores for evaluating older adults' physical and mental health should be age- and gender-specific.

Keywords: health-related quality of life, older adults, self-rated health, self-rated happiness, validation, Yilan study 


\section{INTRODUCTION}

Population aging is dramatically increasing around the world, and evaluating and eliminating health problems for older adults in the community are important aspects of public health. Physical and mental health assessments are major components of comprehensive geriatric assessments (1). For these evaluations, the paper-and-pencil questionnaire remains the most feasible tool, but older adults' cognitive, functional and aging-related vision and hearing losses tend to increase the costs, decrease the validity and reduce older people's willingness to participate in these evaluations. Therefore, valid, simple, and easy ways to measure physical and mental health are important to community-based geriatric medicine. Asking a general or global question has the advantage of being a relatively low-cost way to easily collect, score and interpret these valuable data.

Global self-rated health measures have been widely applied in general populations, developing countries, militaries, and many societies, and they have been found to adequately and objectively indicate physical health, mental health, chronic diseases, unhealthy behaviors and physical functioning (2-5). Despite the potential value of global measures, they are not widely used for older adults, partly because their validity has not been established for that age group. It is suspected that global self-ratings might not be sensitive enough to distinguish among subtle individual differences because of older adults' declining physical functionality. However, most of the global self-rated health measures' response options are ordinal scales, which tend to be relatively insensitive to skewed distributions and might compromise validity (6). It has been suggested that a numerical rating scale in response to a global question might be more accurate for measuring older adults' health status (7). To the best of our knowledge, no previous study has investigated the validity of global self-rated health measures with numerical scales for older adults in Asia.

Regarding mental health, global self-rated happiness measures have been developed. Happiness is a combination of positive hedonic, cognitive, and affective states, and individual assessments of personal happiness are influenced by individual, cultural and societal factors (8). Similar to self-rated physical health, the instruments use ordinal response scales (9-11). Moreover, although comprehensive verifications of construct validity should evaluate divergent as well as convergent validity, most global self-rated happiness measures have been assessed for convergent validity using constructs that measure emotions or attitudes, such as life satisfaction (12), or happiness (13). The 12-Item Short Form Health Survey (version 2) [SF-12v2] is a multi-dimensional instrument that comprises physical, mental, emotional, and social health dimensions to evaluate healthrelated quality of life, which is reasonable as an external validator for self-rated health and happiness. Although the physical component summary (PCS) of the SF-12v2 has previously been used to validate global self-rated health (14), no previous study has used its mental component summary (MCS) as an external validator of global self-rated happiness. Besides, we know of just one multi-item self-rated happiness scale of which the divergent validity was assessed using depression and anxiety (15). Further, similar to measures of self-rated health, no global self-rated happiness measure with numerical scales has been assessed regarding its construct validity in older adults.

Therefore, the present study investigated validity of a global self-rated health measure and of a global self-rated happiness measure. The sample was a large cohort of community-dwelling older adults. A comprehensive set of external validators, including SF-12v2 was used to evaluate construct validity and the criterion validity of the two self-rated measures.

\section{METHODS}

\section{Participants}

The data used for this study were derived from the Yilan Study, a community health survey conducted by the Community Medicine Research Center of National Yang-Ming University and National Yang-Ming University Hospital in Taiwan. The data were collected between January 2012 and November 2016. The household registration lists were protected under the personal data protection law of Taiwan and, therefore, a sample was randomly selected from all city residents aged 65 years or older living in Yilan City. Trained interviewers went to the participants' homes for face-to-face interviews. The final sample comprised 3,982 individuals. The details of the sampling methods have been previously reported $(16,17)$. The institutional review board of National Yang-Ming University Hospital (IRB No. 2011A016) approved the study. Informed written consent was obtained from all the participants, and all methods were performed according to the relevant guidelines and regulations.

\section{Instruments \\ Verifying Convergent and Divergent Validity of the Global Self-Rated Health Measure}

The participants were asked to self-rate their general health status on a scale of zero to 100 where higher scores indicated better health. They answered the following question: "How would you rate your present health status?" The PCS of the SF-12v2 was used to assess the convergent validity of the global self-rated health measure. The Chinese translation of the SF-12v2 previously was found to be a valid instrument (18). The Groningen Activity Restriction Scale (GARS) was used to assess the divergent validity of the global self-rated health measure. The GARS is considered a valid measure for assessing disability in activities of daily living (ADLs) and instrumental activities of daily living (IADLs) in older people (19).

\section{Verifying Convergent and Divergent Validity of the Global Self-Rated Happiness Measure}

The participants evaluated their happiness by responding to the question: "In general, how would you rate your current state of happiness?" They rated themselves on a scale of zero to 100 and higher scores indicated more happiness. To assess the convergent validity of global self-rated happiness, the Mental Component Summary (MCS) of the SF-12v2 was used. The Chinese translation of this part of the SF-12v2 is considered valid (18). The Hospital Anxiety and Depression Scale (HADS) was used to determine the divergent validity of the global self-rated 
health measure. The HADS is a reliable instrument used to measure clinical and subclinical anxiety and depression in the general population $(20,21)$, and the Chinese translation of the HADS is considered valid (22).

\section{Criterion Validity of the Global Self-Rated Health and Happiness Measures}

Previous studies that investigated the cut-off scores for PCS or MCS for predicting physical or mental health outcomes (23-25) implied the inclusiveness of the SF-12v2 regarding overall health status. Thus, the two components' scores were effective options for assessing optimal physical and mental health scores with respect to global questions. A previous study has used the SF-12v2 as a validation instrument for global self-rated health (14). The PCS and the MCS use norm-based scoring in which scores higher (or lower) than 50 indicate better (or worse) physical (or mental) health relative to that of a given sample's population (26). In addition, previous studies have found that cut-off values on the PCS and MCS below 50 points were related to poor physical and mental health, respectively $(23-25,27)$. Accordingly, the present study used a score of 50 or higher on the PCS and MCS as the cut-off scores to indicate the optimal self-rated health and happiness scores in the self-rated measures, respectively. Regarding criterion validity, the receiver operating characteristics (ROC) curve was used to determine the cut-off scores on global self-rated health and happiness based on a score of 50 in the PCS and MCS.

\section{Statistical Analysis}

The Chi-Square goodness-of-fit test was used to compare the demographic characteristics of the sample to those of the Yilan city population. Pearson's correlation coefficients were calculated to investigate the relationships among the two global measures, PCS, MCS, GARS, and HADS. The size of the correlation is defined as high, moderate, and low by scores of: $0.70-0.89,0.40-0.69$, and $0.10-0.39$, respectively (28). A stepwise multivariable linear regression analysis estimated the associations between the PCS and self-rated health and between the MCS and self-rated happiness. A general linear model was used to compare the between-group differences in self-rated health and in selfrated happiness with and without controlling for the effects of gender and age. The Youden's index was calculated from the ROC curve to determine the optimal cut-off scores for self-rated health and happiness based on cut-off scores of 50 on the PCS and MCS, respectively. All statistical tests were two-tailed, and $p<0.05$ was considered statistically significant. The statistical software package SPSS for Windows, Version 19.0 (SPSS Inc., Chicago, IL, USA) was used to perform all the analyses.

\section{RESULTS}

\section{Sample Characteristics}

Table 1 presents the sample's demographic characteristics. About $57 \%$ of the sample was female, and compared to the registered residents of Yilan who were aged $\geq 65$ in 2012 (29), the sample was significantly older $\left(\chi^{2}=99.2, \mathrm{df}=1, p<0.001\right)$ and more likely to be female $\left(\chi^{2}=21.1, \mathrm{df}=1, p<0.001\right)$. The PCS mean
TABLE 1 | Descriptive statistics $(n=3,982)$.

\begin{tabular}{|c|c|c|c|c|}
\hline Variable & $\begin{array}{l}\text { Number of } \\
\text { cases }(n)\end{array}$ & $\begin{array}{l}\text { Percentage } \\
(\%)\end{array}$ & Mean & $\begin{array}{l}\text { Standard } \\
\text { deviation }\end{array}$ \\
\hline \multicolumn{5}{|c|}{ Age (in years) } \\
\hline $65-74$ & 1,841 & 46.2 & & \\
\hline 75 or older & 2,141 & 53.8 & & \\
\hline \multicolumn{5}{|l|}{ Gender } \\
\hline Male & 1,711 & 43.0 & & \\
\hline Female & 2,271 & 57.0 & & \\
\hline \multicolumn{5}{|c|}{ Self-rated measures } \\
\hline \multicolumn{3}{|c|}{ Self-rated health (range: 0-100) } & 69.0 & 12.5 \\
\hline \multicolumn{3}{|c|}{ Self-rated happiness (range: 0-100) } & 74.0 & 14.5 \\
\hline \multicolumn{5}{|c|}{ Short Form-12v2 } \\
\hline \multicolumn{3}{|c|}{ Physical Component Summary (PCS) (range: 11.6-71.1) } & 46.7 & 10.0 \\
\hline \multicolumn{3}{|c|}{ Mental Component Summary (MCS) (range: 10.4-77.8) } & 57.9 & 8.3 \\
\hline \multicolumn{3}{|c|}{ Groningen activity restriction scale (GARS) (range: 18-72) } & 23.7 & 12.3 \\
\hline \multicolumn{3}{|c|}{ Hospital Anxiety And Depression Scale (HADS) (range: 0-36) } & 4.6 & 5.0 \\
\hline
\end{tabular}

TABLE 2 | Bivariate correlation matrix among the six measures of health and happiness $^{\mathrm{a}}(n=3,982)$.

\begin{tabular}{|c|c|c|c|c|c|c|}
\hline Measure & 1 & 2 & 3 & 4 & 5 & 6 \\
\hline 1. PCS & 1 & & & & & \\
\hline 2. MCS & $0.038^{*}$ & 1 & & & & \\
\hline 3. HADS & $-0.264^{\star \star \star}$ & $-0.583^{\star \star \star}$ & 1 & & & \\
\hline 4. GARS & $-0.766^{\star \star \star}$ & $-0.355^{\star \star \star}$ & $0.319^{\star \star \star}$ & 1 & & \\
\hline $\begin{array}{l}\text { 5. Global self-rated } \\
\text { health }\end{array}$ & $0.471^{\star \star \star}$ & $0.249^{\star \star \star}$ & $-0.318^{\star \star \star}$ & $-0.316^{\star \star \star}$ & 1 & \\
\hline $\begin{array}{l}\text { 6. Global self-rated } \\
\text { happiness }\end{array}$ & $0.310^{\star \star \star}$ & $0.357^{\star \star \star}$ & $-0.423^{\star \star \star}$ & $-0.264^{\star \star \star}$ & $0.600^{\star \star \star}$ & 1 \\
\hline
\end{tabular}

${ }^{*} p<0.05,{ }^{* * *} p<0.001$.

aPCS, physical component summary; MCS, mental component summary; HADS, hospital anxiety and depression scale; GARS, groningen activity restriction scale.

was 46.7, and the MCS mean was 57.9. The self-rated health mean was 69 , and the self-rated happiness mean was 74 .

\section{Convergent and Divergent Validity}

Table 2 shows the bivariate correlation coefficients among the self-rated health, self-rated happiness, PCS, MCS, GARS, and HADS variables. Regarding global self-rated health, the convergent validity was tested by the correlation between global self-rated health and PCS $(r=0.471, p<0.001)$ and divergent validity was indicated by the correlation between global self-rated health and GARS $(r=-0.316, p<0.001)$. Regarding global self-rated happiness, the correlation between global self-rated happiness and MCS assessed convergent validity $(r=0.357$, $p<0.001)$ and the correlation between global self-rated health and HADS assessed divergent validity $(r=-0.423, p<0.001)$. The overall sizes of correlations between global self-rated health and happiness with external validators were low to moderate. In addition, the correlation between self-rated health and self-rated happiness was high $(r=0.600, p<0.001)$. 
TABLE 3 | Stepwise multivariable linear regressions for the associations of global self-rated health and happiness with the Physical Component Summary (PCS, Model $1^{\mathrm{a}}$ ) and Mental Component Summary (MCS, Model $2^{\mathrm{a}}$ ).

\begin{tabular}{|c|c|c|c|c|c|c|c|}
\hline \multicolumn{4}{|c|}{ Model 1: PCS } & \multicolumn{4}{|c|}{ Model 2: MCS } \\
\hline Variable & B & $95 \% \mathrm{Cl}$ & Cum $R^{2}$ & Variable & B & $95 \% \mathrm{Cl}$ & Cum $R^{2}$ \\
\hline Global self-rated health & 0.351 & $0.330,0.373$ & 0.221 & Global self-rated happiness & 0.179 & $0.159,0.200$ & 0.127 \\
\hline Gender (ref.: female) & & & & Gender (ref.: female) & & & \\
\hline Male & 0.564 & $0.027,1.101$ & 0.248 & Male & 0.917 & $0.434,1.400$ & 0.130 \\
\hline Age (in years; ref.: 75+) & & & & Age (in years; ref.: 75+) & & & \\
\hline $65-74$ & 3.128 & $2.596,3.661$ & 0.247 & $65-74$ years & 0.555 & $0.076,1.034$ & 0.133 \\
\hline Global self-rated happiness & - & - & - & Global self-rated health & 0.029 & $0.005,0.053$ & 0.131 \\
\hline
\end{tabular}

${ }^{a}$ Final models are shown; unstandardized coefficients (B), 95\% Confidence Intervals (Cl), and cumulative $R^{2}$ (Cum $\left.R^{2}\right)$.

TABLE 4 | Mean differences in global self-rated health and global self-rated happiness among the participants with PCS scores at or above the mid-score and MCS scores at or above the mid-score by age group and gender ${ }^{\text {. }}$

\begin{tabular}{|c|c|c|c|c|c|c|c|c|c|c|c|c|}
\hline \multirow[t]{3}{*}{ Variable } & \multicolumn{6}{|c|}{ Global self-rated health } & \multicolumn{6}{|c|}{ Global self-rated happiness } \\
\hline & \multicolumn{3}{|c|}{$\mathrm{PCS} \geq 50$} & \multicolumn{3}{|c|}{$M C S \geq 50$} & \multicolumn{3}{|c|}{$\mathrm{PCS} \geq 50$} & \multicolumn{3}{|c|}{$M C S \geq 50$} \\
\hline & Mean & SD & $p$ & Mean & SD & $p$ & Mean & SD & $p$ & Mean & SD & $p$ \\
\hline \multicolumn{13}{|l|}{ Age } \\
\hline $65-74$ & 73.6 & 10.7 & 0.018 & 70.6 & 11.6 & 0.015 & 78.0 & 13.4 & 0.966 & 76.7 & 13.4 & $<0.001$ \\
\hline $75+$ & 74.7 & 10.8 & & 69.6 & 12.4 & & 78.0 & 12.2 & & 74.8 & 13.1 & \\
\hline \multicolumn{13}{|l|}{ Gender } \\
\hline Male & 74.6 & 10.8 & 0.04 & 70.9 & 12.0 & 0.001 & 78.1 & 12.5 & 0.549 & 76.2 & 13.0 & 0.076 \\
\hline \multirow[t]{2}{*}{ Female } & 73.6 & 10.7 & & 69.5 & 12.0 & & 77.8 & 13.1 & & 75.3 & 13.5 & \\
\hline & EMM & $95 \% \mathrm{Cl}$ & $p$ & EMM & $95 \% \mathrm{Cl}$ & $p$ & EMM & $95 \% \mathrm{Cl}$ & $p$ & EMM & $95 \% \mathrm{Cl}$ & $p$ \\
\hline \multicolumn{13}{|l|}{$\mathrm{Age}^{\mathrm{b}}$} \\
\hline $65-74$ & 73.7 & $73.0,74.3$ & 0.034 & 70.8 & $70.1,71.4$ & 0.006 & 78.0 & $77.2,78.8$ & 0.970 & 76.8 & $76.2,77.5$ & $<0.001$ \\
\hline $75+$ & 74.7 & $74.0,75.4$ & & 69.6 & $69.0,70.2$ & & 78.0 & $77.1,78.8$ & & 74.8 & $74.2,75.4$ & \\
\hline \multicolumn{13}{|l|}{ Gender $^{c}$} \\
\hline Male & 74.6 & $73.9,75.3$ & 0.086 & 70.9 & $70.3,71.6$ & $<0.001$ & 78.1 & $77.3,79.0$ & 0.567 & 76.3 & $75.7,77.0$ & 0.026 \\
\hline Female & 73.8 & $73.1,74.4$ & & 69.4 & $68.9,70.0$ & & 77.8 & $77.0,78.6$ & & 75.3 & $74.7,75.9$ & \\
\hline
\end{tabular}

aPCS, physical component summary; MCS, mental component summary; EMM, estimated marginal mean.

${ }^{b}$ Estimates are gender adjusted.

${ }^{c}$ Estimates are age adjusted.

To examine the relationships between the PCS and the MCS and the two global self-rated measures, stepwise multivariable linear regression analysis was performed. The goal was to determine the strengths of the associations. Table 3 shows the results. Model 1 shows that, net of the effects of age and gender, global self-rated health was related to PCS $\left(R^{2}=0.221\right)$. With every unit increase in the global self-rated health, the PCS increased by 0.351 . In Model 2, global self-rated health and global self-rated happiness related to MCS, and the relationship of global self-rated happiness was stronger than that of global self-rated health $\left(R^{2}=0.127\right)$. With every unit increase in the global self-rated happiness, the MCS increased by 0.179 .

\section{Criterion Validity}

The mean global self-rated health scores were significantly different by age and gender among the participants with PCS scores of 50 or higher (Table 4). Controlling for gender differences, the mean PCS score was still significantly higher among those aged 75 years or older compared to the younger participants. Among the participants with MCS scores of 50 or higher, the mean global self-rated happiness score was significantly different by age (those younger than 75 had a higher mean score) and gender (the males' mean was higher than the females' mean) even after controlling for the effects of gender or age (Table 4). Therefore, because of the gender and age differences, we calculated optimal scores for global self-rated health and global self-rated happiness separately by age and gender.

At a score of 50 on the PCS, the global self-rated health measure's cut-off scores were calculated as 68.5 overall, 68.5 for males, 67.0 for females, 67.0 for those aged 65-74 years, and 69.0 for those aged 75 or older (Table 5). At a score of 50 on the MCS, the cut-off scores on the global self-rated happiness measure were calculated as 69.5 overall, 69.5 for males, 62.5 for females, 69.5 for 
TABLE 5 | Optimal cut-off scores on global self-rated health and global self-rated happiness when the PCS and MCS cut-offs are scores of ' 50 '; $n=3,982$.

\begin{tabular}{lcc}
\hline Group & $\begin{array}{c}\text { Physical component } \\
\text { summary (PCS) }\end{array}$ & $\begin{array}{c}\text { Mental component summary } \\
\text { (MCS) }\end{array}$ \\
\cline { 2 - 3 } & $\begin{array}{c}\text { Optimal cut-off scores on } \\
\text { global self-rated health }\end{array}$ & $\begin{array}{c}\text { Optimal cut-off scores on } \\
\text { global self-rated happiness }\end{array}$ \\
\hline Total sample & 68.5 & 69.5 \\
Gender & & \\
Male & 68.5 & 69.5 \\
Female & 67.0 & 62.5 \\
Age (in years) & & 69.5 \\
65-74 & 67.0 & 62.5 \\
$75+$ & 69.0 & \\
\hline
\end{tabular}

those younger than 75 years, and 62.5 for those aged 75 years or older (Table 5). Figures 1, 2 illustrate ROC curves among total participants and subgroups. The sensitivity, specificity and area under curve are shown in the Table S1.

\section{DISCUSSION}

Using a large number of elderly participants in Taiwan and various measurements as external validators, this study verified global measures of self-rated health and happiness, which differentially represent physical and mental dimensions of elders' health, respectively. In addition, cut-off scores for evaluating elderly adults' physical and mental health should be determined depending on age and gender.

Although the present study found global self-rated health and happiness were correlated with each other, the global self-rated health measure had a stronger relationship to the PCS, supporting the results of a previous study (14). That previous study also examined the relationship between global self-rated health and MCS (14). Although the present study found that global self-rated health significantly related to MCS, it was not a stronger association than that of global self-rated happiness with MCS. Our findings suggest that the PCS was a relatively better validator of global self-rated health and MCS was a relatively better validator of global self-rated happiness.

Gender related to the measures of self-rated health and happiness. Many previous studies have found that women rate their health lower than men rate their health (30-32). We found a similar gender difference, which might be because men generally compare their health to other men, whereas women tend to rate their health based on their family members' opinions (33). However, the gender difference regarding global self-rated happiness was inconsistent with previous results. One previous study found that women reported higher happiness than men in the past, but men had higher happiness than women at present (34). We found that men had higher self-rated happiness than women. Therefore, it is important to understand gender differences in self-rated health and happiness among older adults.

Self-rated health is believed to decrease with age $(35,36)$, but whether the influence of age continues into old age is unclear. Several previous studies found better self-rated health among older than younger old people $(37,38)$. Our results support these findings. A previous study on age-related changes in self-rated health among older men considered age, time and cohort effects and found that self-rated health was influenced by time, but there were no age or cohort effects (39). The researchers explained the absence of an age effect first by evoking the reference-group hypothesis, which contends that, among older people who perceive poor health and disability as their age-related norm, those who are relatively healthy rate their health positively. Another explanation was the health survivor effect, which proposes that people who do not have serious health problems are more likely to survive to older ages, so their assessments are objectively accurate.

Age also has been positively associated with happiness, and older people have been found to self-rated happiness higher than younger people $(40,41)$. The socio-emotional selectivity theory proposes that older people accumulate emotional wisdom that helps them to select emotionally satisfying activities and experiences (40); however, similar to self-rated health, it is not clear whether the influence of age on self-rated happiness continues into old age. Indeed, the age-happiness relationship among older people is often not discussed (40,41). However, a recent study reported that happiness declined among very old people in Europe (42).

We found that the participants aged 75 or older with MCS scores of 50 or higher were less happy than their younger counterparts, which contradicts the socio-emotional selectivity theory. One previous study reported that older Chinese people had a high prevalence of mental disorders (43), which might contribute to low self-rated happiness. Moreover, our sample was drawn from the population of Yilan, which is an agricultural suburb. If they compared themselves to younger old people, the older old people in our sample might have thought they had fewer resources and less social support and rated themselves as less happy (42).

The present study argued the 100-point numerical rating scale is better than other scales to measure self-rated health and happiness. First, scores can be obtained in written or oral form, and it is simple to administer and score. It is reasonable for older adults who might be illiterate or have vision or hearing problems. In contrast, the visual analog scale can be administered only in writing. Second, regarding the psychometric criteria of reliability and predictive validity, there is the advantage of having 101 response options (44-46), which is likely to appeal to researchers concerned with the limited response options offered by ordinal scales (7). Third, it has the advantage over ordinal scales of being able to assess criterion validity.

This study had several strengths. First, the sample size of participants was large. Second, face-to-face interviews at the participants' homes reduced information bias. Third, it was the first study to determine the corresponding cutoff scores on global self-rated health and global self-rated happiness relative to the PCS and MCS separately by gender and age group. However, it had some limitations. First, the sample's demographic characteristics differed from that of the registered elderly residents of Yilan city. However, because this study was not an epidemiological survey, the sociodemographic representativeness of this sample is not 


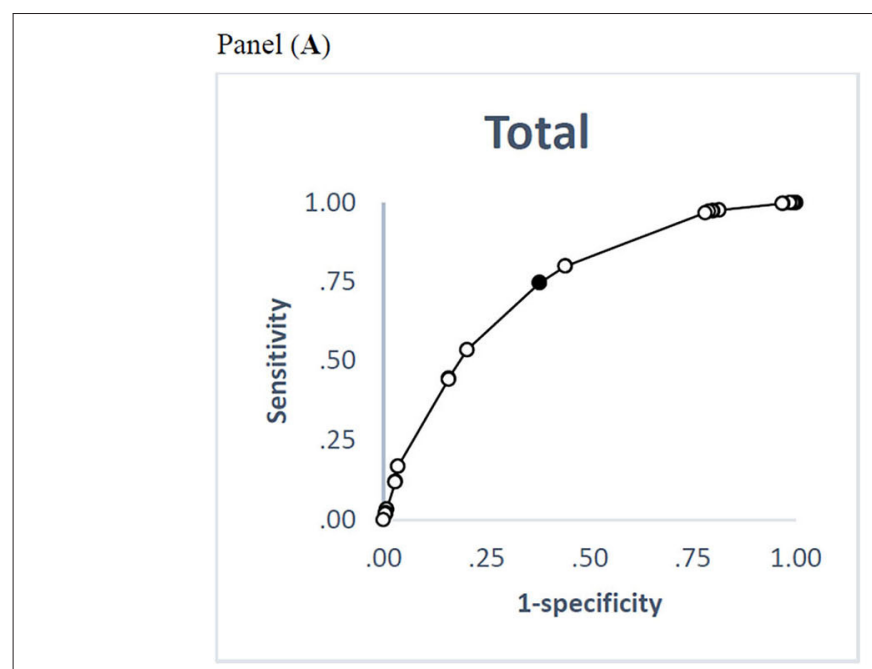

Panel (B)

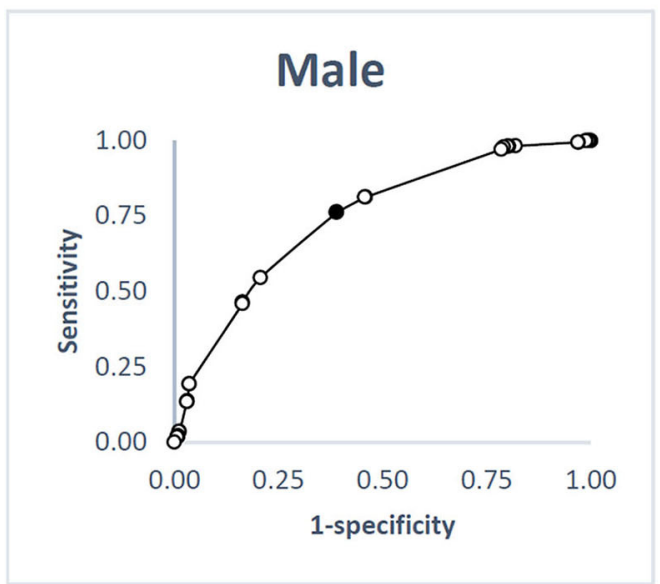

Panel (D)

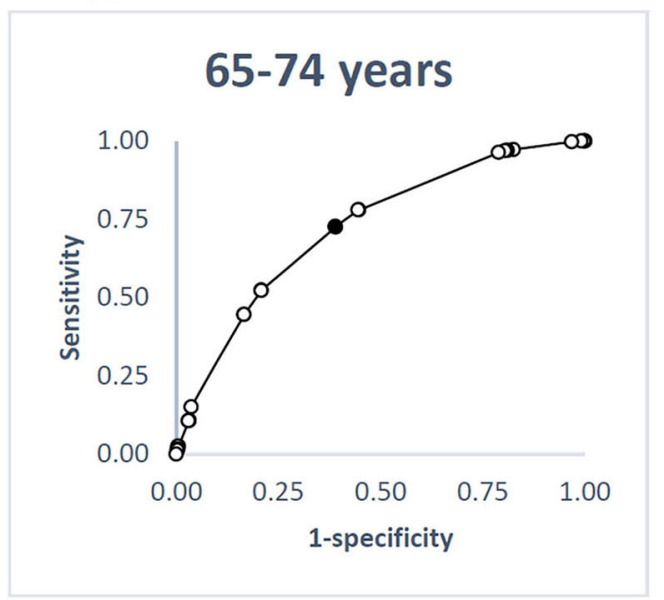

Panel (C)

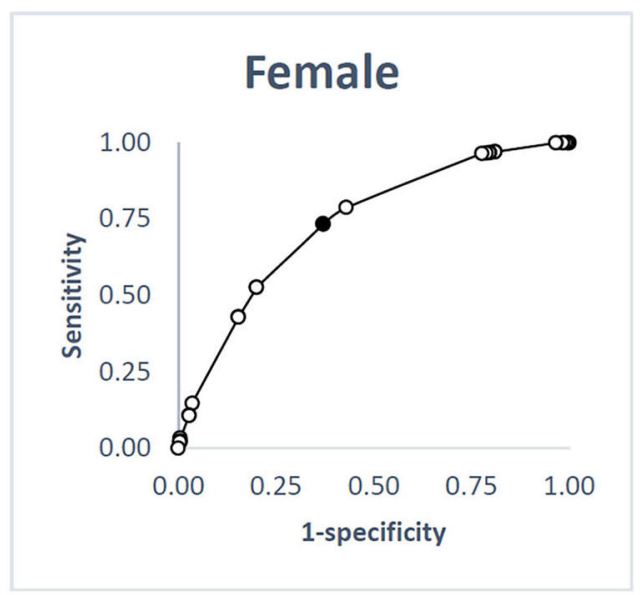

Panel (E)

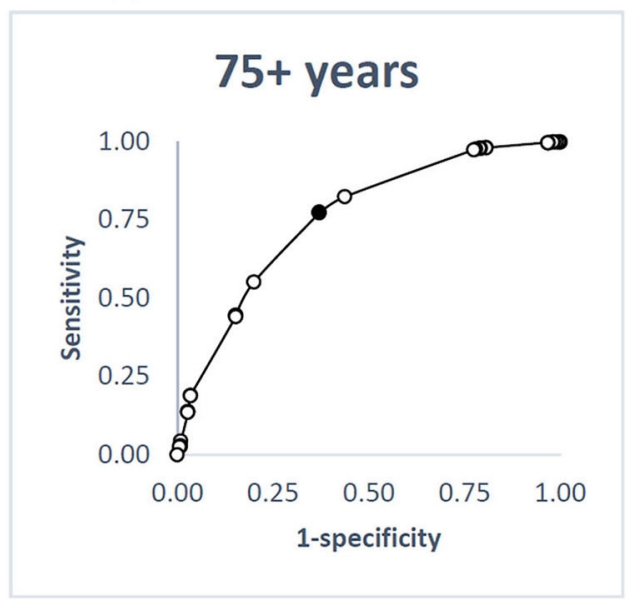

FIGURE 1 | ROC curves for global self-rated health relative to the PCS cut-off scores of 50. (A) Total participants; (B) male; (C) female; (D) 65-74 years; (E) $75+$ years. Black point indicates the optimal cut-off point. ROC, receiver operating characteristics; PCS, physical component summary.

expected to compromise the generalizability of our findings. In contrast, the physical and cognitive demanding nature of our interview protocol suggests that the generalizability of our findings is limited to community-dwelling older adults with no serious physical and cognitive disability. The generalizability of our findings in additional populations 


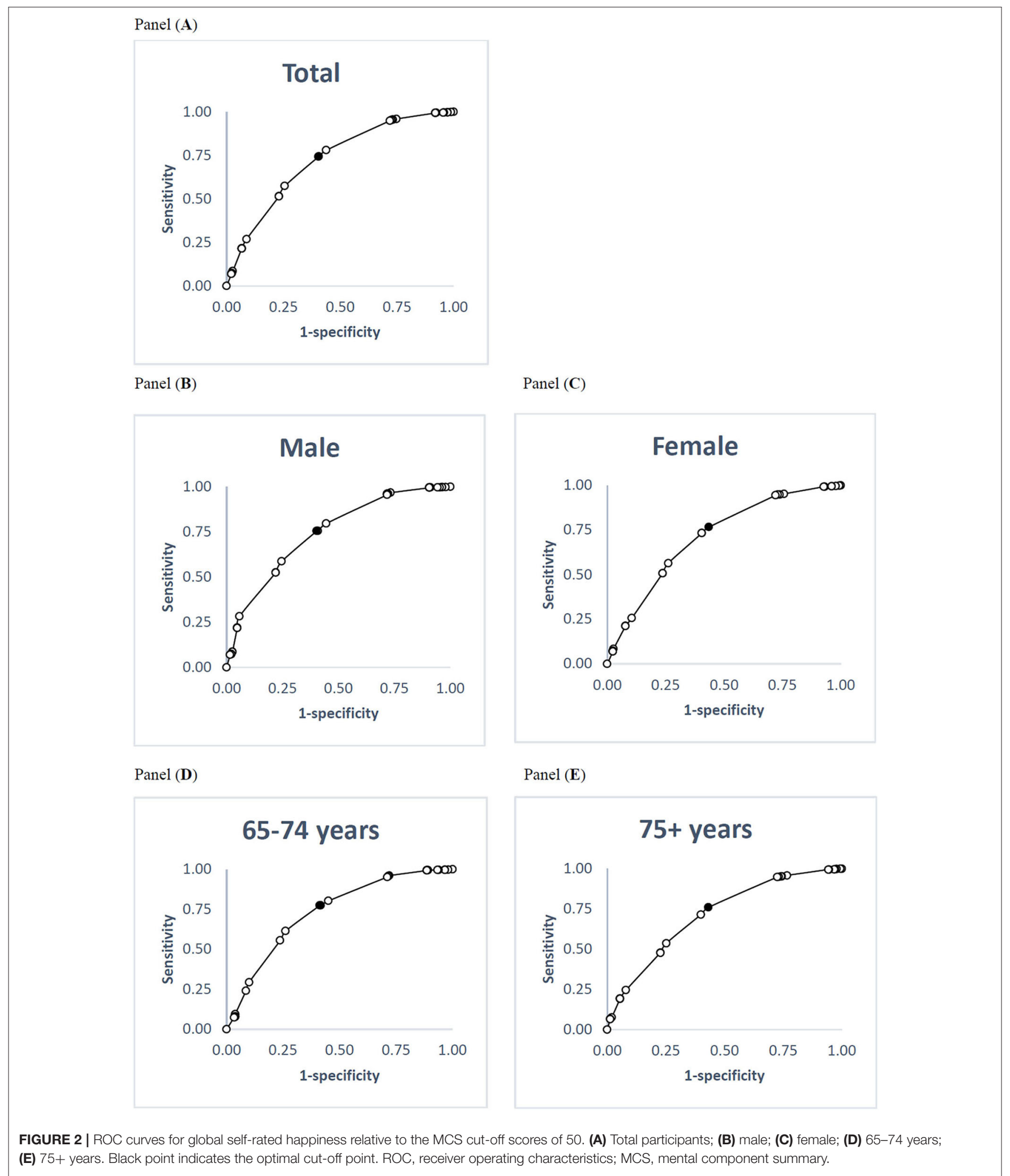

such as those institutionalized and with severe disabilities should be further examined in the future. Second, it was not clear that the SF-12v2 was the most appropriate instrument for older people because health-related quality of life among older people might be focused on physical aspects at the expense of other quality-of-life dimensions (47). 
However, targeted measures have not yet been developed for older adults.

\section{CONCLUSION}

This study's results suggest that global measures of self-rated health and self-rated happiness are valid instruments for quick assessments of the physical and mental health states of Chinese older adults, who reside in the community, remain socially active, and do not have any serious disability. Further, the cut-off scores we calculated to indicate optimal physical and mental health scores seemed to be age- and gender-specific, and the reasons for age and gender differences in global self-rated health and self-rated happiness among older adults should be investigated.

\section{DATA AVAILABILITY STATEMENT}

The datasets generated for this study are available on request to the corresponding author.

\section{ETHICS STATEMENT}

The studies involving human participants were reviewed and approved by Institutional Review Board of National Yang-Ming University Hospital (IRB No. 2011A016). The patients/participants provided their written informed consent to participate in this study.

\section{REFERENCES}

1. Devons CA. Comprehensive geriatric assessment: making the most of the aging years. Curr Opin Clin Nutr Metab Care. (2002) 5:1924. doi: 10.1097/00075197-200201000-00004

2. Wu S, Wang R, Zhao Y, Ma X, Wu M, Yan X, et al. The relationship between self-rated health and objective health status: a population-based study. BMC Public Health. (2013) 13:320. doi: 10.1186/1471-2458-13-320

3. Cullati S, Mukhopadhyay S, Sieber S, Chakraborty A, Burton-Jeangros C. Is the single self-rated health item reliable in India? A construct validity study. BMJ Glob Health. (2018) 3:e000856. doi: 10.1136/bmjgh-2018-000856

4. Haddock CK, Poston WS, Pyle SA, Klesges RC, Vander Weg MW, Peterson A, et al. The validity of self-rated health as a measure of health status among young military personnel: evidence from a cross-sectional survey. Health Qual Life Outcomes. (2006) 4:57. doi: 10.1186/1477-7525-4-57

5. Perez-Zepeda MU, Belanger E, Zunzunegui MV, Phillips S, Ylli A, Guralnik J. Assessing the validity of self-rated health with the short physical performance battery: a cross-sectional analysis of the international mobility in aging study. PLoS ONE. (2016) 11:e0153855. doi: 10.1371/journal.pone. 0153855

6. Preston CC, Colman AM. Optimal number of response categories in rating scales: reliability, validity, discriminating power, and respondent preferences. Acta Psychol. (2000) 104:1-15. doi: 10.1016/S0001-6918(99)00050-5

7. Jensen MP, Karoly P, Braver S. The measurement of clinical pain intensity: a comparison of six methods. Pain. (1986) 27:117-26. doi: 10.1016/0304-3959(86)90228-9

8. Weech-Maldonado R, Miller MJ, Lord JC. The Relationships among sociodemographics, perceived health, and happiness. Appl Res Qual Life. (2017) 12:289-302. doi: 10.1007/s11482-017-9517-8

9. Parker MG, Thorslund M, Nordstrom ML. Predictors of mortality for the oldest old. A 4-year follow-up of community-based elderly in Sweden. Arch Gerontol Geriatr. (1992) 14:227-37. doi: 10.1016/0167-4943(92)90023-W

\section{AUTHOR CONTRIBUTIONS}

Y-HL and N-WH initiated the study. Y-HL, N-WH, and H-CC managed the data collection, performed the data analysis, and wrote the first draft of the manuscript. Y-HL, N-WH, H-CC, and $\mathrm{PC}$ are collectively responsible for interpreting the results and reviewed critically subsequent drafts of the manuscript. All authors contributed to its design read and approved the final manuscript.

\section{FUNDING}

This work was supported by the National Yang-Ming University Hospital, Taiwan under Grant (RD2019-008).

\section{ACKNOWLEDGMENTS}

The authors would also like to thank Yang-Ming Crusaders, Mr. Da-Wei Lin, Ms. Yu-Hui Lin, Mr. Chia-Hsiang Lin and Ms. Tzu-Chun Lo for their help with data collection.

\section{SUPPLEMENTARY MATERIAL}

The Supplementary Material for this article can be found online at: https://www.frontiersin.org/articles/10.3389/fpubh. 2020.00346/full\#supplementary-material

10. Ryuichi Kawamoto TD. Self-reported functional ability predicts threeyear mobility and mortality in community-dwelling older persons. Geriatr Gerontol Int. (2002) 2:68-74. doi: 10.1046/j.1444-1586.2002.00024.x

11. Jo HS, Moon JY, Kim BG, Nam EW. Analysis of socio-demographics, self-rated health, social capital, and happiness in a mediumsized healthy city, Republic of Korea. J Lifestyle Med. (2015) 5:68-75. doi: 10.15280/jlm.2015.5.2.68

12. Cheung F, Lucas RE. Assessing the validity of single-item life satisfaction measures: results from three large samples. Qual Life Res. (2014) 23:280918. doi: 10.1007/s11136-014-0726-4

13. Abdel-Khalek AM. Measuring happiness with a single-item scale. Soc Behav Pers. (2006) 34:139-50. doi: 10.2224/sbp.2006.34.2.139

14. DeSalvo KB, Fisher WP, Tran K, Bloser N, Merrill W, Peabody J. Assessing measurement properties of two single-item general health measures. Qual Life Res. (2006) 15:191-201. doi: 10.1007/s11136-005-0887-2

15. Malone C, Wachholtz A. The relationship of anxiety and depression to subjective well-being in a mainland chinese sample. J Relig Health. (2018) 57:266-78. doi: 10.1007/s10943-017-0447-4

16. Hsu NW, Tsao HM, Chen HC, Chou P. Anxiety and depression mediate the health-related quality of life differently in patients with cardiovascular disease and stroke-preliminary report of the Yilan study: a population-based community health survey. PLoS oNE. (2014) 9:e107609. doi: 10.1371/journal.pone.0107609

17. Hsu NW, Tsao HM, Chen HC, Lo SS, Chen SA, Chou P. Different impacts of atrial fibrillation and cardiac premature contractions on the health-related quality of life in elderly people: the Yilan study. Tohoku J Exp Med. (2016) 238:75-83. doi: 10.1620/tjem.238.75

18. Tseng HM LJ, Tsai YJ. Assessment of health-related quality of life in Taiwan (II): norming and validation of SF-36 Taiwan version. Taiwan J Public Health. (2003) 22:512-8. doi: 10.6288/TJPH2003-22-06-10

19. Kempen GI, Miedema I, Ormel J, Molenaar W. The assessment of disability with the groningen activity restriction scale. conceptual 
framework and psychometric properties. Soc Sci Med. (1996) 43:1601-10. doi: 10.1016/S0277-9536(96)00057-3

20. Bjelland I, Dahl AA, Haug TT, Neckelmann D. The validity of the hospital anxiety and depression scale. an updated literature review. J Psychosom Res. (2002) 52:69-77. doi: 10.1016/S0022-3999(01)00296-3

21. Zigmond AS Snaith RP. The hospital anxiety and depression scale. Acta Psychiatr Scand. (1983) 67:361-70. doi: 10.1111/j.1600-0447.1983.tb09716.x

22. Leung $\mathrm{CM}$, Ho S, Kan CS, Hung $\mathrm{CH}$, Chen $\mathrm{CN}$. Evaluation of the Chinese version of the hospital anxiety and depression scale. a cross-cultural perspective. Int J Psychosom. (1993) 40:29-34. doi: 10.1037/t05677-000

23. Goh GS, Liow MHL, Yeo W, Ling ZM, Guo CM, Yue WM, et al. Poor baseline mental health does not influence improvement in patient-reported outcomes, satisfaction, and return to work two years after single-level anterior cervical discectomy and fusion. Spine (Phila Pa). (2019) 44:83947. doi: 10.1097/BRS.0000000000002960

24. Kusleikaite N, Bumblyte IA, Kuzminskis V, Vaiciuniene R. The association between health-related quality of life and mortality among hemodialysis patients. Medicina. (2010) 46:531-7. doi: 10.3390/medicina 46080076

25. Vilagut G, Forero CG, Pinto-Meza A, Haro JM, de Graaf R, Bruffaerts $\mathrm{R}$, et al. The mental component of the short-form 12 health survey (SF-12) as a measure of depressive disorders in the general population: results with three alternative scoring methods. Value Health. (2013) 16:564-73. doi: 10.1016/j.jval.2013.01.006

26. Maruish ME, DeRosa MA. A Guide to the Integration of Certified Short Form Survey Scoring and Data Quality Evaluation Capabilities. Lincoln, RI: QualityMetric, Incorporated (2009).

27. DiBonaventura M, Andrews LM, Yadao AM, Kahler KH. The effect of gout on health-related quality of life, work productivity, resource use and clinical outcomes among patients with hypertension. Expert Rev Pharmacoecon Outcomes Res. (2012) 12:821-9. doi: 10.1586/erp.12.60

28. Schober P, Boer C, Schwarte LA. Correlation coefficients: appropriate use and interpretation. Anesth Analg. (2018) 126:17638. doi: 10.1213/ANE.0000000000002864

29. Office YCHR. Household Registration Statistics Data. (2019). Retrieved from: https://ilhhr.e-land.gov.tw/cp.aspx?n=2B3911AF933DF44D (accessed March 15, 2018).

30. Chang HT, Hsu NW, Chen HC, Tsao HM, Lo SS, Chou P. Associations between body mass index and subjective health outcomes among older adults: findings from the Yilan Study, Taiwan. Int J Environ Res Public Health. (2018) 15:ijerph15122645. doi: 10.3390/ijerph15122645

31. Dong W, Wan J, Xu Y, Chen C, Bai G, Fang L, et al. Determinants of self-rated health among shanghai elders: a cross-sectional study. BMC Public Health. (2017) 17:807. doi: 10.1186/s12889-017-4718-5

32. Eriksson I, Unden AL, Elofsson S. Self-rated health. Comparisons between three different measures. Results from a population study. Int J Epidemiol. (2001) 30:326-33. doi: 10.1093/ije/30.2.326

33. af Sillen U, Nilsson JA, Mansson NO, Nilsson PM. Self-rated health in relation to age and gender: influence on mortality risk in the Malmo Preventive Project. Scand J Public Health. (2005) 33:183-9. doi: 10.1080/14034940410019235
34. Stevenson B, Wolfers J. Happiness Inequality in the United States. J Legal Stud. (2008) 37:S33-79. doi: 10.1086/592004

35. Moum T. Self-assessed health among Norwegian adults. Soc Sci Med. (1992) 35:935-47. doi: 10.1016/0277-9536(92)90108-3

36. Goldstein MS, Siegel JM, Boyer R. Predicting changes in perceived health status. Am J Public Health. (1984) 74:611-4. doi: 10.2105/AJPH.74.6.611

37. Hays JC, Schoenfeld DE, Blazer DG. Determinants of poor self-rated health in late life. Am J Geriatr Psychiatry. (1996) 4:188-96. doi: 10.1097/00019442-199622430-00002

38. Idler EL. Age differences in self-assessments of health: age changes, cohort differences, or survivorship? J Gerontol. (1993) 48:S289-300. doi: 10.1093/geronj/48.6.S289

39. Hoeymans N, Feskens EJ, van den Bos GA, Kromhout D. Age, time, and cohort effects on functional status and self-rated health in elderly men. Am J Public Health. (1997) 87:1620-5. doi: 10.2105/AJPH.87.10.1620

40. Steptoe A, Deaton A, Stone AA. Subjective wellbeing, health, and ageing. Lancet. (2015) 385:640-8. doi: $10.1016 /$ S0140-6736(13)6 1489-0

41. Blanchflower DG, Oswald AJ. Is well-being U-shaped over the life cycle? Soc Sci Med. (2008) 66:1733-49. doi: 10.1016/j.socscimed.2008. 01.030

42. Morgan J, Robinson O, Thompson T. Happiness and age in European adults: the moderating role of gross domestic product per capita. Psychol Aging. (2015) 30:544-51. doi: 10.1037/pag0000034

43. Xu G, Chen G, Zhou Q, Li N, Zheng X. Prevalence of mental disorders among older chinese people in Tianjin city. Can J Psychiatry. (2017) 62:778-86. doi: 10.1177/0706743717727241

44. Lozano Luis M. García-Cueto E, Muñiz J. Effect of the number of response categories on the reliability and validity of rating scales. Methodology. (2008) 4:73-9. doi: 10.1027/1614-2241.4.2.73

45. Maydeu-Olivares A, Kramp U, Garcia-Forero C, Gallardo-Pujol D, Coffman $D$. The effect of varying the number of response alternatives in rating scales: experimental evidence from intra-individual effects. Behav Res Methods. (2009) 41:295-308. doi: 10.3758/BRM.41.2.295

46. Revilla M, Saris W, Krosnick J. Choosing the number of categories in agree-disagree scales. Sociol Methods Res. (2014) 43:73-97. doi: 10.1177/0049124113509605

47. Netuveli G, Blane D. Quality of life in older ages. Br Med Bull. (2008) 85:113-26. doi: 10.1093/bmb/ldn003

Conflict of Interest: The authors declare that the research was conducted in the absence of any commercial or financial relationships that could be construed as a potential conflict of interest.

Copyright $\odot 2020$ Lin, Chen, Hsu and Chou. This is an open-access article distributed under the terms of the Creative Commons Attribution License (CC BY). The use, distribution or reproduction in other forums is permitted, provided the original author(s) and the copyright owner(s) are credited and that the original publication in this journal is cited, in accordance with accepted academic practice. No use, distribution or reproduction is permitted which does not comply with these terms. 